\title{
Effect of prepartum grouping strategy on displacements from the feed bunk and feeding behavior of dairy cows
}

\author{
K. M. Lobeck-Luchterhand, ${ }^{\star}$ P. R. B. Silva, ${ }^{\star}$ R. C. Chebel, $†$ and M. I. Endres ${ }^{\star 1}$ \\ *Department of Animal Science, and \\ †Department of Veterinary Population Medicine, University of Minnesota, St. Paul 55108
}

\begin{abstract}
The objective of the current study was to determine whether providing stable pen management affected displacements from the feed bunk and feeding behavior of prepartum dairy cows. Two hundred and twenty-four nonlactating Jersey primiparous and multiparous cows were enrolled in the study. The 2 treatments were allin-all-out (AIAO; 44 cows were moved into the close-up prepartum pen as 1 group, with no additions during the 5-wk repetition) or traditional (TRD; with weekly entrance of new cows to maintain a pen density of 44 cows). Cows ( $253 \pm 3 \mathrm{~d}$ of gestation) were balanced for parity and projected 305-d mature-equivalent milk yield and assigned randomly to either AIAO or TRD treatments. At enrollment, cows with a body condition score $<2$ or $>4$ (1-5 scale; $1=$ emaciated and $5=$ obese $)$ or with a locomotion score $>3(1-5$ scale; $1=$ normal gait and $5=$ severely lame) were not included. Displacements from the feed bunk were measured weekly for both treatments when TRD cows were moved into the close-up pen ( $\mathrm{d} 0$ ) and additionally on $\mathrm{d} 1,2,3$, and 7 for $3 \mathrm{~h}$ after fresh feed delivery. A displacement rate was created to take into account differences in stocking density throughout the experiment. Displacement rate was calculated as the number of displacements divided by the number of cows in the pen at that time. Feeding behavior was measured using video 10-min scan sampling for 24 -h periods at d $0,1,2$, and 7 . Displacements and feeding behavior were recorded for all $5 \mathrm{wk}$ of each repetition. Treatment $\times$ week interactions were detected for number of displacements and displacement rate. The TRD treatment had more displacements from the feed bunk than AIAO in wk 1, 3, and 5, with no differences in wk 2 and 4. Similarly, the TRD treatment had a greater displacement rate than the AIAO treatment in wk 1 and 5, with a tendency in wk 3 . No differences between the treatments were detected in wk 2 and 4 . A treatment $\times$ week interaction existed for
\end{abstract}

Received August 21, 2013.

Accepted February 5, 2014

${ }^{1}$ Corresponding author: miendres@umn.edu feeding time. Cows housed in the AIAO treatment had longer average feeding times in wk 2 with a tendency in wk 3, but spent 39 fewer minutes eating than those in the TRD treatment during the wk 1 of the study. Housing prepartum close-up cows with stable pen management reduced displacements from the feed bunk and altered average daily feeding times.

Key words: prepartum dairy cow, feeding behavior, social behavior

\section{INTRODUCTION}

The transition period (considered 3 wk before to 3 wk after parturition; Grummer, 1995) is a critical time for the dairy cow. During this period, cows experience physiological, immune, and nutritional changes that make the cow at risk for metabolic and infectious diseases (Goff and Horst, 1997). Dry matter intake depression occurs during the final 2 to 3 wk before parturition, yet is a time when demand for nutrients is increasing (Grummer et al., 2004). Up to $25 \%$ of cows are culled or die during the first 60 DIM (Godden et al., 2003), which could be attributed to an unsuccessful transition period. Minimizing stressors during the transition period may allow for a successful transition from the nonlactating to the lactating stage.

On large commercial dairy farms, cows are commonly subjected to many pen changes during their lactation and dry period (Grant and Albright, 2001). One strategy recommended to nutritionally manage prepartum dairy cows is to have a far-off and a close-up dry period (Watters et al., 2008). These pens are typically subjected to once-per-week or twice-per-week inclusions of new animals after cows leave the pen for calving to maintain a desired stocking density. These pen movements may disrupt the social dynamics of the group and negatively affect DMI (Cook and Nordlund, 2004). When dairy cattle are subjected to regrouping, increased physical agonistic behaviors, such as displacements, threats, and butting, and a decrease in milk production occur (von Keyserlingk et al., 2008). Prepartum cows moved into a new pen had reductions in DMI and rumination time, and these moved cows displaced other cows already pre- 
viously in the pen twice as frequently after regrouping (Schirmann et al., 2011). These negative physical interactions usually moderated $3 \mathrm{~d}$ after regrouping (Kondo and Hurnik, 1990). The lower-ranking animals seemed to be the most affected by regrouping. These animals spent more time standing without eating and ate at a faster rate, putting the animal at risk for ruminal acidosis and lameness events (Proudfoot et al., 2009).

Nordlund et al. (2006) recommended that producers adopt a stable social grouping during the prepartum period to minimize social disruptions. Cows with a similar calving date can be grouped together during the prepartum close-up period and stay in that pen until calving or calve in bedding pack pens (Cook, 2009). During this time no new cows are added to the pen until all to most of the current animals have calved. A disadvantage of the stable pen management system is the need for additional pens, which increases building cost. Cook (2009) recommends sizing the pens to accommodate $140 \%$ of the average weekly calving rate with stable pen management. At times, pens will be underused while a few remaining cows await parturition. A study that examined stable pen management versus a dynamic pen did not find a difference in the number of displacements from the feed bunk, DMI, plasma NEFA concentrations, and milk production up to 30 DIM (Coonen et al., 2011). In that study, approximately 1 cow was added at a time to a small pen with only 10 cows. Additionally, cows in their study calved in the dry cow pen. It is unknown whether these results would be similar to movements of small groups of cows into a larger pen, with cows being moved to a calving pen as they near parturition, similar to conditions experienced on large commercial dairies.

The objective of our study was to examine whether having a stable social group or all-in-all-out (AIAO) treatment during the close-up prepartum period would alter the number of displacements from the feed bunk or total daily feeding time compared with cows housed under traditional (TRD) pen management, with weekly entrance of new animals in a large dairy setting. We hypothesized that the AIAO treatment would result in fewer displacements from the feed bunk and a longer daily feeding time than the TRD treatment.

\section{MATERIALS AND METHODS}

\section{Animals and Housing}

A total of 224 primiparous and multiparous nonlactating Jersey cows were allocated to 4 groups (2 treatments $\times 2$ replications) from June to September 2011 . The study was conducted at a large commercial dairy farm (6,400 lactating animals) in south-central Minne- sota. Prepartum cows were provided a TMR once daily at approximately $0500 \mathrm{~h}$ and fed from a feed alley by headlocks. Feed was pushed up frequently throughout the day by farm personnel.

When cows demonstrated signs of calving, farm personal moved the cows to an individual box stall. At d 1 postcalving, cows were moved into a freestall pen with 240 stalls and 260 headlocks stocked at $100 \%$ based on the number of stalls for $21 \mathrm{~d}$. Video observation ceased when the cows left the dry period treatment pens.

\section{Experimental Treatments and Design}

At enrollment, all cows were in $\geq 1$ lactation. Cows were required to have a BCS between 2 and 4 (1-5 scale; $1=$ emaciated and $5=$ obese) and a locomotion score $<3(1-5$ scale; $1=$ normal gait and $5=$ severely lame) or were not included in the study. Cows $253 \pm 3$ $\mathrm{d}$ in gestation were balanced for parity ( 1 or $\geq 2$ lactation) and projected 305-d mature-equivalent milk yield at enrollment and were assigned to 1 of the 2 study pens. The 2 treatments were AIAO: 44 cows assigned to a pen as a group and no new cows added during a 5 -wk period $(\mathrm{n}=2$, with a total of 88 cows $)$ or TRD treatment: weekly entrance of new cows to maintain a pen density of 44 cows after cows in the pen calved (n $=2$, with a total of 136 cows). During the initial week of each replicate, 44 cows entered the AIAO treatment, with no new cows entering the pen during the 5 -wk observation period. During the initial week, cows enrolled in the TRD treatment were added to a group of closeup cows to reach a pen stocking density of 44 cows. New cows were enrolled weekly in the TRD treatment pen to maintain a stocking density of 44 cows (92\% feed bunk; $100 \%$ stall stocking density) across the study period. At the end of the 5-wk replicate, a new TRD and AIAO group started, but treatments switched pens to avoid location bias.

Two experimental pens housing 44 cows each were used. The pens were on either side of a feed lane in a 12-row low-profile cross-ventilated freestall barn and located on one end of the middle rows of the barn adjacent to the dairy's additional, nonexperimental close-up prepartum pens. Both experimental pens had the same measurements of $31.7 \times 11.0 \mathrm{~m}$, and had 44 sand-bedded freestalls [229 (length) $\times 107$ (width) $\times$ 114 (height) $\mathrm{cm}$ ] with a head-to-head configuration and forty-eight $0.61-\mathrm{m}$ headlocks $(92 \%$ feed bunk stocking density). Two water troughs were located in the pen and measured $366 \times 56 \mathrm{~cm}$. One water trough was located at the end of the bank of freestalls and a shared water trough was located between the treatment pen and an adjacent nonexperimental pen. Hourly pen temperatures were collected for the duration of the study 
using a data logger (HOBO H8 Pro Series; temperature accuracy $\pm 0.5^{\circ} \mathrm{C}$; Onset Computer Corp., Bourne, MA) placed $3 \mathrm{~m}$ above the bedding surface. Temperatures were averaged over the $3 \mathrm{~h}$ of feed bunk displacement observation period and averaged over $24 \mathrm{~h}$ for the feeding behavior analysis.

\section{Behavior Measurements}

All enrolled cows were identified with a unique alphanumeric symbol on both sides of their rib cage using permanent hair dye either in black or blonde. Hair dye was applied at either $\mathrm{d}-1$ or 0 before cows were moved to the treatment pens.

Social Behavior. To observe social interactions while feeding, each pen was equipped with 3 video cameras (Weldex Corp., Cypress, CA) connected to a digital video recording system (Channel Vision Technology, Costa Mesa, CA). Displacements from the feed bunk were measured continuously for $3 \mathrm{~h}$ on the day of move-in immediately after cows were moved at 1300 $\mathrm{h}(\mathrm{d} 0)$ and following fresh feed delivery $(0500 \mathrm{~h})$ on $\mathrm{d}$ $1,2,3$, and 7 of each 5 -wk observation period. From continuous video observation, an interaction between 2 cows was considered a displacement from the feed bunk when physical contact initiated by 1 cow caused the receiving cow to stop feeding, back out, and entirely remove her head from the headlock (Endres et al., 2005). To account for changes in stocking density, a displacement rate was calculated as daily displacements divided by the number of cows in the pen for each day of observation. This correction was needed for both treatments, because cows were removed after calving in both pens and cows were added to the TRD treatment only once per week (similarly to what would happen in a dairy farm). Both displacements from the feed bunk and the displacement rate were averaged daily for each week of the entire 5 -wk observation period.

Feeding Behavior. Feeding time was measured using 10-min video scan sampling for 24 -h periods at d 0 , 1, 2, and 7 (Endres et al., 2005). A cow was considered eating when the cow's ears were on the feed alley side of the headlocks. Daily feeding times (min) were calculated by summing the daily 10-min scan samples and multiplying that value by 10 . To determine the percentage of cows eating at the feed bunk, the number of cows eating was summed at each 10-min scan sample. Only observation days with 40 or more cows in the pen were included in the percentage of cows at the feed bunk analysis.

\section{Statistical Analysis}

The UNIVARIATE procedure of SAS (SAS Institute Inc., Cary, NC) was used to examine normality and for the presence of outliers for the number of displacements, displacement rate and feeding times. A linear mixed model (PROC MIXED; SAS Institute Inc.) was built to evaluate the effect of close-up prepartum grouping management and the outcome variables of number of displacements, displacement rate, and feeding time. Pen was used as the experimental unit. Individual cow data were averaged for each treatment replicate to obtain an average pen value for statistical analysis. Observation day within week was a repeated measure for both feeding and displacement behaviors. The repeated statement was used for analysis of repeated measurements and the compound symmetry structure of covariance was chosen according to the Bayesian Akaike information criteria. Treatment (TRD vs. AIAO) was the fixed effect for all models. Covariates examined for number of displacements and displacement rate included average daily pen parity, average days prepartum, pen temperature, week, and the treatment $\times$ week interaction. Covariates examined for feeding time included parity, average daily pen temperature, stall stocking density, days to parturition, week, and treatment $\times$ week interaction. Least squares means and standard errors were determined using the LSMEANS statement in the MIXED procedure. Least squares means comparisons of the treatment $\times$ week interaction were separated with PDIFF. The TTEST procedure was used to determine if the percentage of cows eating during a 24-h period differed between the treatments at each observed time point. The remaining data (temperature, humidity, and treatment parity) were analyzed with repeated measurements over time using PROC MIXED of SAS (version 9.1.3, 2005; SAS Institute Inc.).

\section{RESULTS}

The mean temperature in the barn during the study was $21.6^{\circ} \mathrm{C}$ and ranged from 11.4 to $30.7^{\circ} \mathrm{C}$. The mean relative humidity was $80.0 \%$ and ranged from 42.8 to $100 \%$. No difference in temperature and humidity existed between treatments. Average parity did not differ between AIAO and TRD treatments $(1.6 \pm 0.1$ vs. 1.7 $\pm 0.1 ; \mathrm{LSM} \pm \mathrm{SE}$, respectively). Once weekly, a mean of $10.4 \pm 3.1$ cows (range: $6-16$ cows) were added to the TRD group.

\section{Social Behavior}

A treatment $\times$ week interaction was observed for mean daily number of displacements from the feed bunk (Figure 1). The TRD treatment had more displacements from the feed bunk during wk 1,3 , and $5(P$ $<0.05)$ than the AIAO treatment, whereas no differ- 


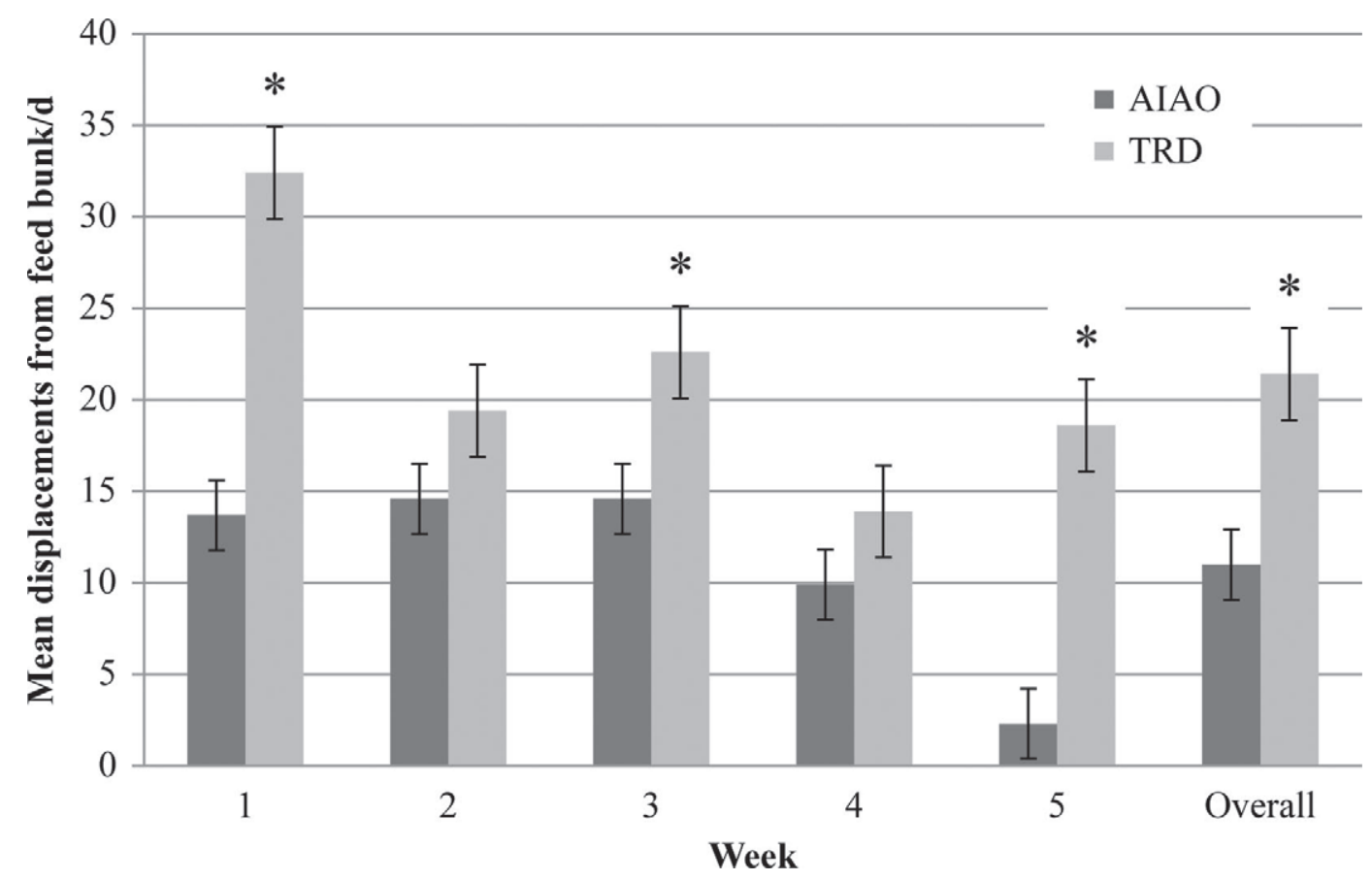

Figure 1. Mean number of displacements (no./d) from the feed bunk for cows housed under stable [all-in-all-out (AIAO)] management or with weekly entrance of new animals in traditional (TRD) pen management during the close-up prepartum period. ${ }^{*}$ denotes significant differences between treatments $(P<0.05)$ within week.

ences in the number of displacements existed between the treatments during wk 2 and 4.

Within the AIAO treatment, fewer displacements were observed during wk 5 than during wk 1 to $4(P<$ 0.05 ), but the number of displacements during wk 1 to 4 did not differ from each other. Week 1 of the TRD treatment had a greater frequency of displacements from the feed bunk than during wk 2 to $5(P<0.05)$. Additionally, a greater number of displacements were observed during wk 3 of the TRD treatment compared with wk $4(P<0.05)$.

A treatment $\times$ week interaction was detected for displacement rate between the AIAO and TRD treatments (Figure 2). The TRD treatment had a greater $(P<0.05)$ displacement rate than the AIAO treatment during wk 1 and $5(0.78 \pm 0.07$ and $0.46 \pm 0.07$ vs. 0.33 \pm 0.06 and $0.19 \pm 0.06$, respectively), a tendency $(P=$ $0.066)$ for greater displacements during wk $3(0.56 \pm$ 0.06 vs. $0.40 \pm 0.06$, respectively), and was similar to $\mathrm{AIAO}$ in wk 2 and 4.

\section{Feeding Behavior}

A treatment $\times$ week interaction was detected for daily feeding times (Figure $3 ; P<0.001$ ). Cows housed in the AIAO treatment spent 39 fewer minutes per day eating during wk 1 than housed in the TRD treatment. During wk 2 of the study, the AIAO treatment cows had a longer average daily feeding time by 25 min than the TRD treatment cows $(P<0.05)$, with a tendency of longer feeding time during wk 3 of the study $(P=$ $0.054)$. No differences were detected between the treatments in feeding times during wk 4 and 5 .

Within the AIAO treatment, wk- 1 feeding times were shorter than wk 2 and 3 , with a tendency during wk $4(P=0.092)$, and did not differ from wk 5 . No other weeks within the AIAO treatment differed. Within the TRD treatment, wk 1 had a longer feeding time than wk 2 and 3 and did not differ from wk 4 and 5. During wk 3, cows in the TRD treatment had shorter daily feeding times than wk 4 and 5 and did not differ from wk 2.

No differences were detected in maximum feed bunk occupancy occurring at fresh feed delivery $(0500 \mathrm{~h})$, with 64.9 and $68.6 \%$ of cows eating at that time for the TRD and AIAO treatments, respectively (Figure 4). In general, the AIAO treatment had a greater percentage of feed bunk occupancy during periods of low feeding activity.

\section{DISCUSSION}

Kondo and Hurnik (1990) defined social stabilization as when the ratio of nonphysical to physical interactions remains fairly stable. Based on data from von Keyserlingk et al. (2008), physical interactions appear 


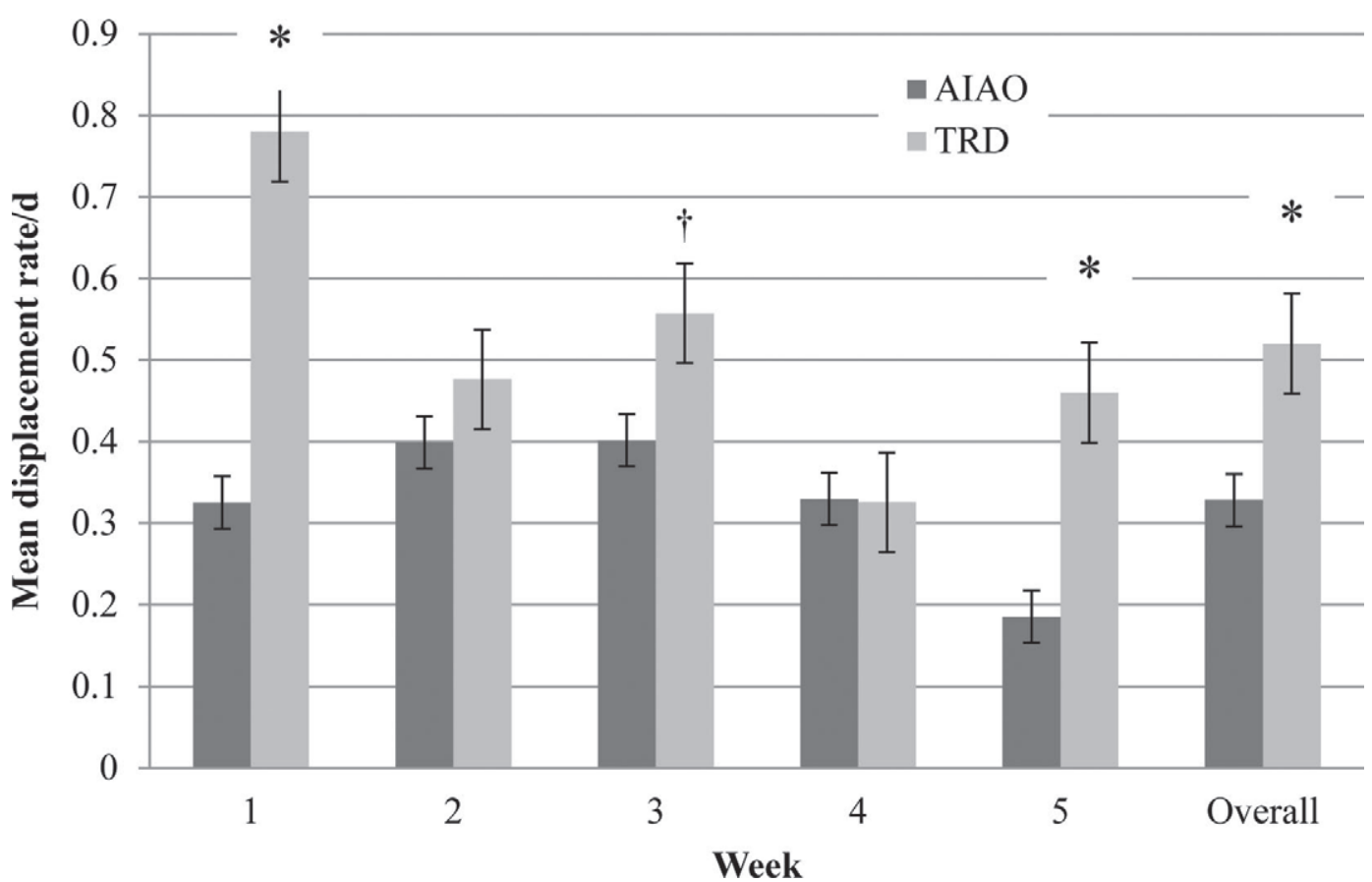

Figure 2. Mean rate of displacements from the feed bunk for cows housed under stable [all-in-all-out (AIAO)] management or with weekly entrance of new animals in traditional (TRD) pen management during the close-up prepartum period. * denotes significant differences between treatments $(P<0.05)$ within week; $\dagger$ denotes a tendency between treatments $(P=0.056)$ within week.

to decrease $3 \mathrm{~d}$ after regrouping for lactating dairy cattle, with approximately $60 \%$ of interactions being nonphysical and 40\% physical (Kondo and Hurnik, 1990).
The AIAO grouping strategy was proposed to minimize physical social interactions during the transition period. Previous research investigating stable versus dynamic

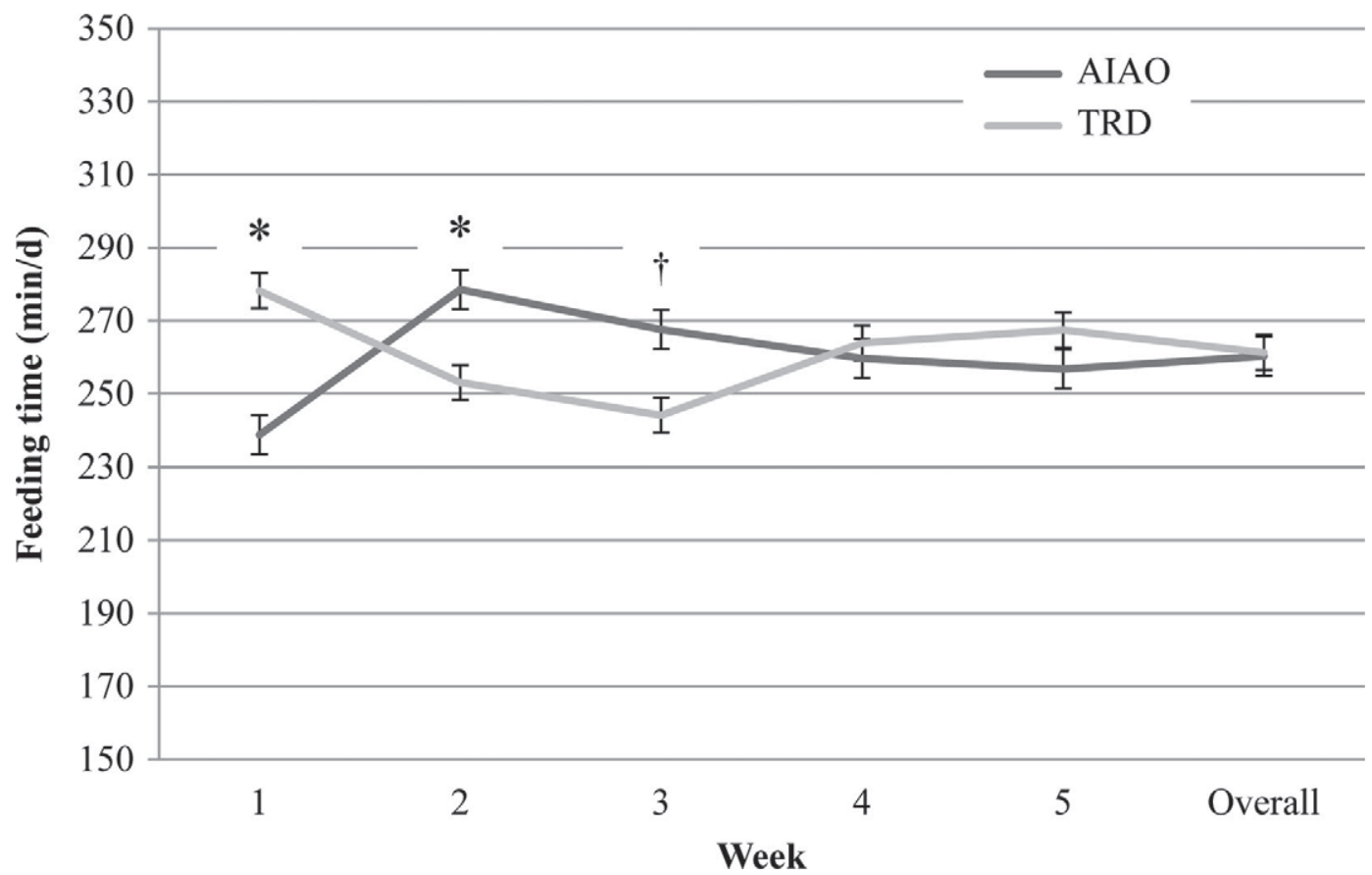

Figure 3. Feeding times of cows housed under stable [all-in-all-out (AIAO)] management or with weekly entrance of new animals in traditional (TRD) pen management during the close-up prepartum period. ${ }^{*}$ denotes significant differences between treatments $(P<0.05)$ within week; $\dagger$ denotes a tendency between treatments $(P=0.054)$ within week. 


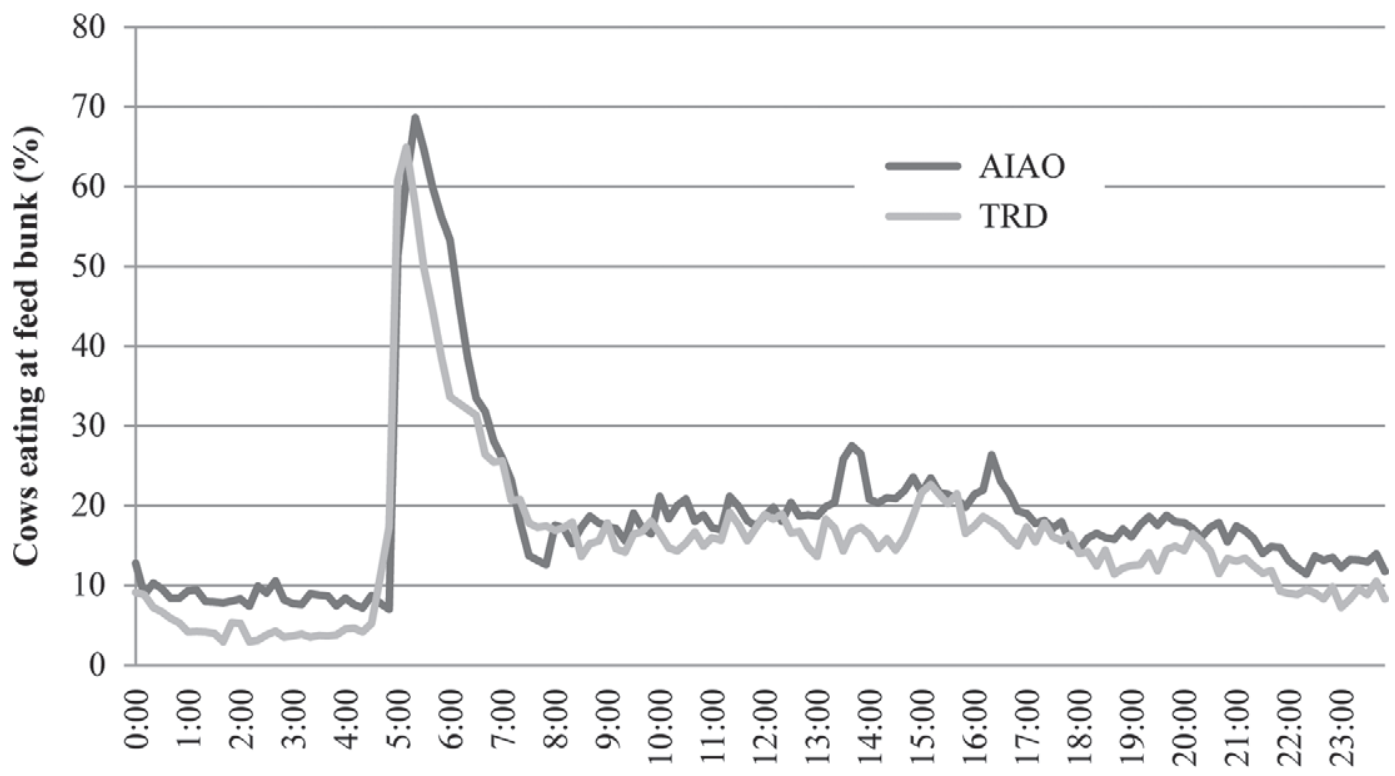

Time

Figure 4. Percentage of cows eating at the feed bunk over a 24-h period under stable [all-in-all-out (AIAO)] management or with weekly entrance of new animals in traditional (TRD) pen management during the close-up prepartum period (data were averaged over $30 \mathrm{~d}$ and only included days when the pen housed greater or equal to 40 cows). Significant differences in percentage eating were found for feeding periods 0030 to 0450,1320 to $1330,1650,1720,2200$ to 2210 , and 2320 to $2340 \mathrm{~h}$.

pen management did not find a difference in feed bunk displacements for prepartum cows (Coonen et al., 2011). Those researchers speculated that minimal disruption would occur with only a small number of animals moving into the dynamic pen. In their study, approximately 1 cow was moved into the pen and this occurred up to 2 times per week. In the current study, approximately 10 cows were moved into the pen once weekly, which may have made the social disruptions more noticeable. Schirmann et al. (2011) observed that prepartum cows that were moved into a new pen displaced cows at the feed bin more frequently than cows that stayed in the home pen. Kondo and Hurnik (1990) reported that the total number of interactions was greatest immediately after regrouping. In the TRD pen each week a group of cows was moved into the pen, likely increasing the social disruption. No noticeable pattern existed in the TRD treatment in regard to the average weekly number of displacements; we suspect that the number of displacements was more determined by the dynamics of the group. In the AIAO treatment, the average weekly displacements were fairly stable from wk 1 to 3 of the study when only a few cows calved. During wk 4 and 5, a marked decrease in displacements was observed, likely due to the increased feeding space available.

The AIAO grouping strategy resulted in a lower stocking density and increased feed bunk space compared with the TRD treatment; although this was unavoidable, we calculated a displacement rate to compensate for this potential confounder. The TRD treatment had a 1.6 times greater displacement rate than the AIAO grouping strategy, even after accounting for stocking density. Cows in this study were provided 0.61 $\mathrm{m}$ of feed bunk space when the pen was stocked at the maximum of 44 animals per pen. Feed bunk space per cow varied from 0.61 to $1.04 \mathrm{~m}$ in the TRD treatment and from 0.61 to $14.6 \mathrm{~m}$ in the AIAO treatment throughout the study. Even during the weeks when the AIAO had similar feed bunk space to TRD, the TRD grouping strategy still had more displacements from the feed bunk than AIAO. When feed bunk space is reduced, an increase in physical displacements is observed (DeVries et al., 2004; Proudfoot et al., 2009). DeVries et al. (2004) reported 57\% fewer aggressive interactions when feed bunk space increased from 0.5 to $1.0 \mathrm{~m}$ per cow. Proudfoot et al. (2009) examined competition at the feed bin (1:1 cow:feed bin or 2:1 cows:feed bin) for 1 wk prepartum and 2 wk postpartum and found that although competition increased displacements, the competition affected primiparous and multiparous animals differently. Multiparous cows housed in the competitive feeding environment spent more time standing without eating than multiparous cows not housed in the competitive environment and no differences were observed in the primiparous groups. Competitively fed multiparous animals spent less time 
feeding 1 wk prepartum and had a tendency for lower DMI, whereas postpartum, these cows did not differ in DMI. However, they compensated with a greater feed intake rate (Proudfoot et al., 2009). In another study, when competition was increased from 1 to 4 cows per feeding station, the lower-ranking animals altered their feed consumption to less-preferred times of the day (Olofsson, 1999). In the current study, we did not examine social rank in relation to feeding time of the day due to the study design; however, we speculate that the lower-ranking animals may have been more affected by the treatment than the group averages might indicate.

It has been hypothesized that creating a stable prepartum group would minimize physical social interactions that would ultimately affect DMI and health during this critical time (Nordlund et al., 2006). When lactating dairy cows were regrouped, they spent $15 \mathrm{~min}$ less time eating during the first hour after regrouping; however, the total feeding time did not differ (von Keyserlingk et al., 2008). Prepartum cows that were regrouped and moved into a new pen saw a decrease in DMI from baseline values, whereas regrouped cows that stayed in their home pen did not differ from their baseline values (Schirmann et al., 2011). In the current study, cows housed in the AIAO treatment had reduced daily feeding time during the first week being housed in the pen compared with those housed in the TRD treatment. We hypothesize that because there were resident cows in the TRD treatment with approximately 10 study cows added to the pen in the beginning of that replication, the pen average may have masked the potential reduction in feeding time experienced by those newly introduced cows or cows already in the pen. Further research on the effect of pen residence time for each individual cow is warranted. Similar to the decrease in DMI that occurs during the last 7 to 10 d of pregnancy (Bertics et al., 1992), cows in the AIAO treatment had a gradual decrease in feeding time from wk 2 to 5 before parturition; however, this reduction was not significant. Feeding times did not have a specific pattern within the weeks for the TRD treatment, likely due to the variation of gestation length within that group. Coonen et al. (2011) examined DMI for 28 d prepartum comparing a stable and a dynamic prepartum grouping strategy, with no differences between the treatments. Dry matter intake was not examined in the current study because the study was performed on a large commercial dairy. However, in a companion study (Silva et al., 2013), we showed that the AIAO grouping strategy did not differ from the TRD treatment in number of disease events, NEFA and BHBA concentrations, or milk production postcalving. Additionally, Coonen et al. (2011) found that a stable pen treatment did not affect plasma NEFA concentrations or milk production up to 30 DIM with Holsteins.

\section{CONCLUSIONS}

In the current study, the AIAO grouping strategy resulted in fewer displacements from the feed bunk than the TRD strategy and this was evident during all weeks of the repetition except during wh 2 and 4 when the treatments did not differ in the number of displacements. Even when accounting for changes in stocking density, the AIAO treatment still had a lower displacement rate than the TRD treatment. The AIAO cows spent fewer minutes eating daily than the TRD cows during wk 1, whereas they had a longer feeding time during wk 2. Our results (with Jersey cows and approximately $92 \%$ feed bunk stocking density) indicate that the AIAO treatment reduced negative social behaviors and altered daily feeding times. More research is needed with various pen stocking densities and other breeds, such as Holsteins.

\section{ACKNOWLEDGMENTS}

The authors thank the owners, managers, and staff of New Sweden Dairy (Nicollet, MN) for allowing us to use their facility and animals. In addition, the authors thank João G. N. Moraes, Luís G. D. Mendonça, Alexandre A. Scanavez, and Gisele Nakagawa (all of University of Minnesota, St. Paul) for their help with animal movements in coordination with the project and Adam Rousar, Angela Henao (both of University of Minnesota, St. Paul), and Ozkan Elmaz (Mehmet Akif Ersoy University, Burdur, Turkey) for help with video analysis.

\section{REFERENCES}

Bertics, S. J., R. R. Grummer, C. Cadorniga-Valino, and E. E. Stoddard. 1992. Effect of prepartum dry matter intake on liver triglyceride concentration and early lactation. J. Dairy Sci. 75:19141922 .

Cook, N. B. 2009. Facility designs to maximize transition cow health and productivity. Pages 13-22 in Proc. West. Can. Dairy Sem., Alberta, Canada. University of Alberta, Department of Agriculture, Food and Nutritional Science, Edmonton, AB, Canada.

Cook, N. B., and K. V. Nordlund. 2004. Behavioral needs of the transition cow and considerations for special needs facility design. Vet. Clin. North Am. Food Anim. Pract. 20:495-520.

Coonen, J. M., M. J. Maroney, P. M. Crump, and R. R. Grummer. 2011. Short communication: Effect of a stable pen management strategy for precalving cows on dry matter intake, plasma nonesterified fatty acid levels, and milk productions. J. Dairy Sci. 94:2413-2417.

DeVries, T. J., M. A. G. von Keyserlingk, and D. M. Weary. 2004. Effect of feeding space on the inter-cow distance, aggression, and feeding behavior of free-stall housed lactating dairy cows. J. Dairy Sci. 87:1432-1438. 
Endres, M. I., T. J. DeVries, M. A. G. von Keyserlingk, and D. M. Weary. 2005. Short communication: Effect of feed barrier design on the behavior of loose-housed lactating dairy cows. J. Dairy Sci. 88:2377-2380

Godden, S. M., S. C. Stewart, J. F. Fetrow, P. Rapnicki, R. Cady, W. Weiland, H. Spencer, and S. W. Eicker. 2003. The relationship between herd rbST supplementation and other factors and risk for removal for cows in Minnesota Holstein dairy herds. Pages 55-64 in Proc. Four-State Nutr. Conf., La Crosse, WI. MidWest Plan Service Publ. MWPS-4SD16. MidWest Plan Service, Ames, IA.

Goff, J. P., and R. L. Horst. 1997. Physiological changes at parturition and their relationship to metabolic disorders. J. Dairy Sci. 80:1260-1268.

Grant, R. J., and J. L. Albright. 2001. Effect of animal grouping on feeding behavior and intake of dairy cattle. J. Dairy Sci. 84(E. Suppl.):E156-E163.

Grummer, R. R. 1995. Impact of changes in organic nutrient metabolism on feeding the transition dairy cow. J. Anim. Sci. 73:28202833.

Grummer, R. R., D. G. Mashek, and A. Hayirli. 2004. Dry matter intake and energy balance in the transition period. Vet. Clin. North Am. Food Anim. Pract. 20:447-470.

Kondo, S., and J. F. Hurnik. 1990. Stabilization of social hierarchy in dairy cows. Appl. Anim. Behav. Sci. 27:287-297.

Nordlund, K., N. Cook, and G. Oetzel. 2006. Commingling dairy cows: Pen moves, stocking density, and health. Pages $36-42$ in Proc. 39th
Annu. Mtg. Am. Assoc. Bovine Pract., St. Paul, MN. Am. Assoc. Bovine Pract., Auburn, AL.

Olofsson, J. 1999. Competition for total mixed diets fed for ad libitum intake using one or four cows per feeding station. J. Dairy Sci. 82:69-79

Proudfoot, K. L., D. M. Veira, D. M. Weary, and M. A. G. von Keyserlingk. 2009. Competition at the feed bunk changes the feeding, standing, and social behavior of transition dairy cows. J. Dairy Sci. 92:3116-3123.

Schirmann, K., N. Chapinal, D. M. Weary, W. Heuwieser, and M. A. G. von Keyserlingk. 2011. Short-term effects of regrouping on behavior of prepartum dairy cows. J. Dairy Sci. 94:2312-2319.

Silva, P. R. B., J. G. N. Moraes, L. G. D. Mendonça, A. A. Scanavez, G. Nakagawa, J. Fetrow, M. I. Endres, and R. C. Chebel. 2013. Effects of weekly regrouping on prepartum dairy cows on metabolic, health, reproductive, and productive parameters. J. Dairy Sci. 96:4436-4446.

von Keyserlingk, M. A. G., D. Olenick, and D. M. Weary. 2008. Acute behavioral effects of regrouping dairy cows. J. Dairy Sci. 91:10111016.

Watters, R. D., J. N. Guenther, A. E. Brickner, R. R. Rastani, P. M. Crump, and R. R. Grummer. 2008. Effects of dry period length on milk production and health of dairy cattle. J. Dairy Sci. 91:25952603. 